\title{
Laboreal
}

Volume $12 \mathrm{~N}^{\circ} 1 \mid 2016$

Os Equipamentos de Proteção Individual (EPI):

protetores, mas nem sempre

\section{"Os equipamentos de proteção individual (EPI): protetores, mas nem sempre": apresentação do dossier}

"Los equipos de protección individual (EPI): protectores, pero no siempre": presentación del dossier

"Les équipements de protection individuelle (EPI): protecteurs, mais pas toujours » : présentation du dossier

"The personal protective equipment (PPE): protective, but not always":

presentation of the thematic dossier

Francisco Duarte, Laurence Théry e Carolina Ullilen-Marcilla

\section{(2) OpenEdition}

Journals

\section{Edição electrónica}

URL: http://journals.openedition.org/laboreal/2830

DOI: $10.4000 /$ laboreal.2830

ISSN: 1646-5237

\section{Editora}

Universidade do Porto

\section{Refêrencia eletrónica}

Francisco Duarte, Laurence Théry e Carolina Ullilen-Marcilla, «"Os equipamentos de proteção individual (EPI): protetores, mas nem sempre": apresentação do dossier », Laboreal [Online], Volume 12 No1 | 2016, posto online no dia 01 julho 2016, consultado o 23 setembro 2020. URL : http:// journals.openedition.org/laboreal/2830; DOI : https://doi.org/10.4000/laboreal.2830

Este documento foi criado de forma automática no dia 23 setembro 2020.

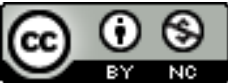

Laboreal está licenciado com uma Licença Creative Commons - Atribuição-NãoComercial 4.0 Internacional. 


\title{
"Os equipamentos de proteção individual (EPI): protetores, mas nem sempre": apresentação do dossier
}

\author{
"Los equipos de protección individual (EPI): protectores, pero no siempre": \\ presentación del dossier \\ «Les équipements de protection individuelle (EPI): protecteurs, mais pas \\ toujours » : présentation du dossier \\ "The personal protective equipment (PPE): protective, but not always": \\ presentation of the thematic dossier
}

Francisco Duarte, Laurence Théry e Carolina Ullilen-Marcilla

\section{NOTA DO EDITOR}

http://dx.doi.org/10.15667/laborealxii0116fd

1 Na edição de julho da revista Laboreal, apresentamos um dossier, que continuará em dezembro, que trata sobre o uso de Equipamentos de Proteção Individual (EPI). Sabe-se que entre os princípios gerais de prevenção dos riscos profissionais, esses equipamentos representam a última barreira contra os riscos a que os trabalhadores estão expostos.

De forma similar a um artigo já publicado na revista Laboreal por Garrigou, Baldi \& Dubuc (2008), o objetivo desse dossier é discutir de forma mais ampla diferentes aspectos muitas vezes desconhecidos dos EPI. Na realidade, a questão da EPI tem sido abordado, já a muito tempo, principalmente a partir de uma abordagem técnica pelos químicos ou especialistas em materiais. Poucos estudos têm abordado as dificuldades 
durante o uso. Isto pode conduzir a um ponto de vista relativamente simplista: bastaria utiliza-los para estar protegido.

3 O ângulo de ataque desta questão é trazer à luz toda a complexidade destes objetos aparentemente simples e de sua utilização. Esta complexidade está relacionada em primeiro lugar à sua concepção e à sua eficácia real que é muitas vezes mal avaliada. Um segundo aspecto desta complexidade está relacionada ao seu uso em situações reais. Os trabalhadores sentem uma série de dificuldades e inconvenientes que interferem no desenvolvimento das suas atividades. Assim, o design desses equipamentos devem assegurar uma proteção ótima, perturbar o menos possível e ainda, o usuário também deve ser informado sobre o uso adequado e a manutenção apropriada a fim de reduzir a exposição.

into de artigos convoca diferentes disciplinas - ergonomia, ciências da saúde ciências jurídicas, economia, antropologia, engenharia da prevenção - e buscando apresentar a complexidade acima mencionada de maneira complementar.

5 Seis artigos constituem a primeira parte desse dossier, publicado nesse numero de julho. Um artigo sobre a exposição ocupacional a produtos químicos foi proposto por Fabienne Goutille, Louis Galey, Clémence Rambaud, Pierrick Pasquereau, José Marçal Jackson $\mathrm{F}^{\circ} \mathrm{e}$ Alain Garrigou. As medidas de prevenção mais comuns estão limitadas aos equipamentos de proteção individual, embora a regulamentação privilegie equipamentos de proteção coletiva. 0 trabalho é apresentado na forma de um estudo de caso. A partir da perspectiva metodológica da ergotoxicología e da antropologia, buscase articular o conhecimento sobre os perigos dos produtos, as modalidades de prescrição dos EPI na empresa, a percepção que tem os trabalhadores dos riscos, os efeitos sobre seus corpos e a eficácia dos EPIs.

6 No que diz respeito ao uso de EPI no setor agrícola, Carolina Ullilén e Alain Garrigou colocam em evidência a influência da percepção de risco na utilização destes equipamentos de proteção contra pesticidas. 0 estudo foi realizado em uma amostra de cinco viticultores, buscando entender as estratégias empregadas para se proteger contra os pesticidas durante a preparação da mistura, a sua aplicação nos campos agrícolas e a limpeza de materiais agrícolas. Os resultados mostram que o nível de formação, a experiência ao longo do tempo e as crenças ou convicções podem influenciar, positiva ou negativamente, na percepção de risco.

7 Maria Cristina Gonzaga e Cristiane Queiroz analisam o processo de certificação de luvas de proteção em corte manual da cana de açúcar e discutem as diferenças entre as normas de teste na fabricação das mesmas e a atividade a ser realizada. São evidenciados a variabilidade do tamanho das mãos para a escolha das luvas, o número de acidentes e de doenças profissionais relacionadas com as mãos. $O$ facão, considerado como o principal instrumento de trabalho, foi modificado pelos trabalhadores para melhorar o seu desempenho e adaptá-lo às exigências do processo de produção. 0 estudo apresenta sugestões oriundas dos trabalhadores para melhoria do projeto das luvas e do facão, sem negligenciar o sistema de certificação.

$\mathrm{O}$ artigo de Alice Turcot e Michel Lehoux aborda o uso de luvas antivibratórias para reduzir a vibração mão-braço. Uma revisão da literatura foi realizada na Medline (PubMed) e EBSCOhost para os anos de 1970 a 2014. Um estudo de campo através de questionários e entrevistas foi realizado com 30 trabalhadores, que foram convidados a utilizar dois tipos de luvas durante um curto período de tempo. Ambas foram consideradas, por vários trabalhadores, como inconfortáveis e incomodavam a 
execução do trabalho. Além disso, a revisão da literatura, revela que a eficácia das luvas para atenuar os níveis de vibração é baixa.

9 Estudo realizado por Marcello Motta Veiga e Carlos Campelo de Albuquerque analisa a permeabilidade dos EPI contra os pesticidas pelos agentes de saúde para combater o mosquito Aedes aegypti. A permeabilidade é uma característica de EPI que os torna inadequados para utilização, o que foi avaliado por método conhecido como pipeta, calculando as percentagens de repulsão, de retenção e de penetração de pesticidas no equipamento de proteção. Os resultados mostram que o tipo de costura influencia na permeabilidade e que uma repulsividade inferior pode não ser suficiente para avaliar a eficácia do EPI.

A pesquisa de Thiara Angeli Porto e Mônica Fatima visou compreender o uso do corpo e sua relação com a saúde e a segurança nos processos de umidificação e tratamento do granito numa organização do estado do Espírito Santo no Brasil. Tendo como base o acompanhamento do processo de trabalho e adotando a postura de um cartógrafo com registros em um diário de bordo e entrevistas com 10 trabalhadores, o estudo ilustra algumas maneiras de usar o corpo na atividade em questão, destacando o uso inadequado de EPI e o potencial dos equipamentos de proteção coletiva para melhoria das condições de trabalho.

11 Agradecimentos a todos os autores por contribuir com seus conhecimentos e experiências.

\section{BIBLIOGRAFIA}

Garrigou, A., Baldi, I. \& Dubuc, P. (2008). Contributos da ergotoxicologia na avaliação da eficácia real dos EPI que devem proteger do risco fitossanitário: da análise da contaminação ao processo colectivo de alerta. Laboreal, 4, (1), 92-103.

\section{AUTORES}

\section{FRANCISCO DUARTE}

Programa de Engenharia de Produção - Universidade Federal do Rio de Janeiro - PEP/COPPE/ UFRJ

Centro de Tecnologia, Bloco G sala G209 - Cidade Universitária. 21945-970 Rio de Janeiro - Brasil duarte@pep.ufrj.br

\section{LAURENCE THÉRY}

Centre d'Ergonomie et de Sécurité du Travail de Picardie (CESTP), Agence Régionale pour l'Amélioration des Conditions de Travail (ARACT), 19, rue V. Hugo, 80000 Amiens - France 1.thery@anact.fr 


\section{CAROLINA ULLILEN-MARCILLA}

Facultad de Ingeniería Ambiental, Escuela Profesional de Ingeniería de Higiene y Seguridad Industrial, Universidad Nacional de Ingeniería, Av. Túpac Amaru 210, Rímac, Lima 21, Perú cullilenm@uni.edu.pe 